\title{
Design and implementation of flexible wearable antenna on thyroid gland in the detection of cancer cells.
}

\author{
Rexiline Sheeba $\mathbf{I}^{1^{*}}$, Jayanthy $\mathrm{T}^{2}$ \\ ${ }^{1}$ Sathyabama Institute of Science \& Technology (Deemed to be University), Chennai, India \\ ${ }^{2}$ Panimalar Institute of Technology, Chennai, India
}

\begin{abstract}
The article brings out an innovative $Z$ shape wearable patch antenna that was designed over textile also the other type of substrates to test its performance over ISM (industrial, scientific, medicine) band of microwave frequencies was discussed. Wearable antenna has the wearable and textile properties bending in 2D, which shows the flexibility for the wearable electronic devices. Since the performance of the antenna is working on ISM band, it is perfectly suitable for biomedical applications. In the proposed antenna silk substrate is chosen for implementation because of its low SAR and is placed on the thyroid gland to detect the cancer cells. The performances of the antenna were varied, when it is placed on the thyroid gland of the human tissue, Tissue properties were considered and analyzed within and without cancer affected areas. Since cancer cells are more water content tissues, the gain and electrical conductivity performance were found changed. While placing the antenna on thyroid gland it is also observed that there is a change in working frequency of the Z-patch silk substrate wearable antenna. The simulated results have been tabulated and measured. The results of the fabricated proposed antenna $S_{11}$ have been shown by using the network analyzer.
\end{abstract}

Keywords: Soft substrate wearable antenna, Dielectric constant, Thyroid gland, Cancer thyroid gland ISM band. Accepted on April 18, 2018

\section{Introduction}

Abnormal large thyroid gland is goiter. Both diffuse and nodular goiters are usually caused by an imbalance in certain hormones. An undifferentiated carcinoma called as anaplastic carcinoma is one among the rare forms of thyroid cancer. Sometimes develop from an existing papillary or follicular cancer. In this case the cancer cells do not look like normal thyroid cells under the microscope. This cancer often spreads quickly into the neck and also to other parts of the body, and is very difficult to treat. A micro strip patch antenna has a combination of wearable properties and textile properties in two dimensions. A planar structure flexible in $2 \mathrm{D}$ can bend along two planes, optimized to perform in proximity of human body which is said to be a softwear antenna. Shrestha et al., study "Breast tumor detection by flexible wearable antenna system", eliminates the need for liquid coupling medium is used in conventional systems, leading to a simpler and cost effective imaging device [1]. This is achieved by proposing a planar micro strip antenna design on a flexible substrate and optimizing the antenna for the skin contact operation. It is shown that systems with a matched coupling medium still have $20 \%$ theoretical reflection loss at the skin, which is completely eliminated in the proposed system.

Simulation results show 3-fold increase in the current densities and electric fields in the tumor. Experimental results within- house breast and tumor phantoms showed that the received signal from a tumor has $33 \mathrm{~dB}$ maximum and $19 \mathrm{~dB}$ amplitude above noise level [2]. Pankaj et al. proposed a technique which is comparatively easier and safer than mammography and tomography for the detection of breast cancer. Mammography which is currently the most popular method of breast screening has some limitations, and microwave imaging offers an attractive alternative. In this work a cancer diagnosis model which consists of a micro strip antenna, breast model and tumor are designed in HFSS. This model shows that the tumor present in breast can be detected by observing the change in the distribution of volume current density of breast with tumor and without tumor. The model shows that the maximum current density of breast with tumor is $275.61\left(\mathrm{~A} / \mathrm{m}^{\wedge} 2\right)$ and maximum volume current density of breast in absence of tumor is $109.5\left(\mathrm{~A} / \mathrm{m}^{\wedge} 2\right)$. This particular technique is comparatively easier and safer than mammography and tomography in which the high intensity X-rays are used for detection of breast cancer. The overall idea for this innovative concept is to detect with potential benefits of adequate depth penetration via microwave imaging, while minimizing cumulative side effects to healthy tissue due to ionized radiation. Murali et al. study of "Development of wearable antennas with different cotton textiles" using Micro strip patch antenna is introduced [3]. 
The scope of the work is to design an innovative softwear antenna which has the combination of soft textile substrate and wearable properties in $2 \mathrm{D}$ plane and flexible, said to be a softwear antenna. The placement of this proposed softwear antenna on human thyroid gland with and without cancer cells show a variation in the performance of the antenna. This differentiates the cancer and the normal tissues in the thyroid gland [4]. The skin contact interaction between the antenna and tissue properties were shown in tabulation and different observations were made. Simulated and fabricated measured result was also included in the analysis (Figures 1 and 2).

\section{Design of Soft Substrate Wearable Antenna and the Work Flow}

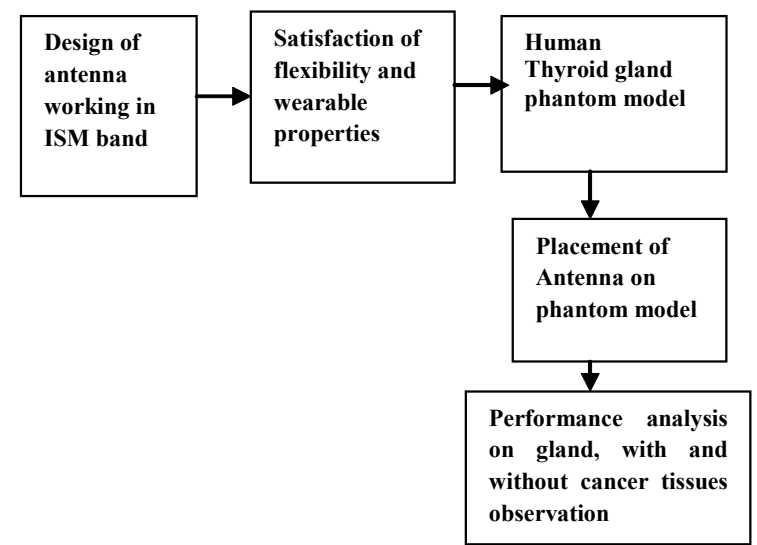

Figure 1. Work flow of the proposed softwear antenna.

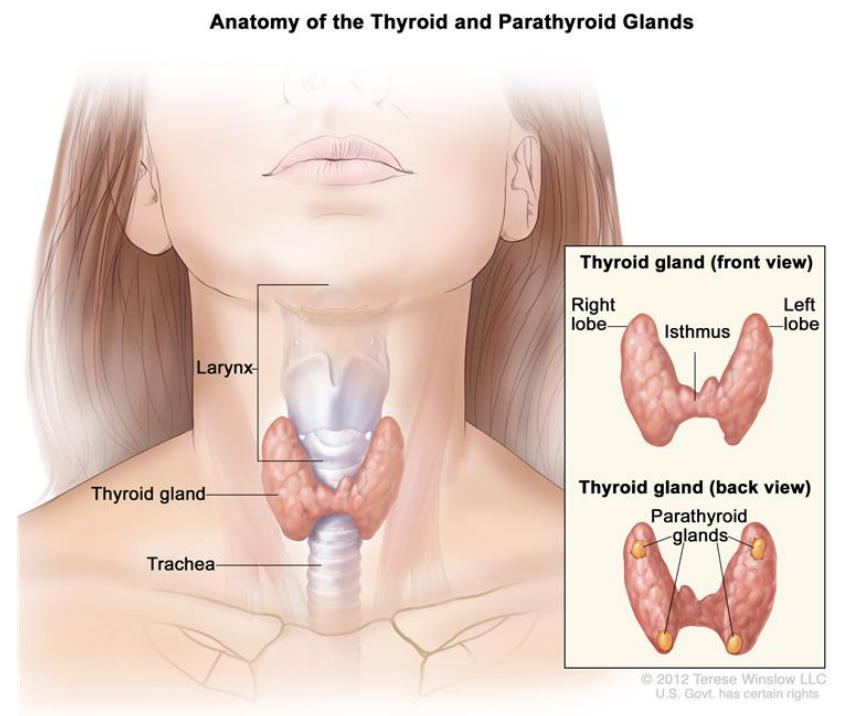

Figure 2. Anatomy of the thyroid and parathyroid glands courtesyGoogle images.

Table 1. Design specifications of Z-patch softwear antenna.

$\begin{array}{lllllll}\begin{array}{l}\text { Width } \\ \text { of the }\end{array} & \begin{array}{l}\text { Length } \\ \text { of the length }\end{array} & \begin{array}{l}\text { Slot } \\ \text { width }\end{array} & \begin{array}{l}\text { Length of } \\ \text { the }\end{array} & \begin{array}{l}\text { Height of } \\ \text { the }\end{array} & \begin{array}{l}\text { Width of } \\ \text { the }\end{array} \\ \begin{array}{l}\text { patch } \\ (\mathrm{mm})\end{array} & \begin{array}{l}\text { patch } \\ (\mathrm{mm})\end{array} & (\mathrm{mm}) & (\mathrm{mm}) & \begin{array}{l}\text { substrate } \\ \text { substrate }\end{array} & \begin{array}{l}\text { substrate } \\ (\mathrm{mm})\end{array} & \\ (\mathrm{mm}) & (\mathrm{mm})\end{array}$

\begin{tabular}{lllllll}
\hline 75 & 22.5 & 53 & 12.5 & 100 & 0.254 & 75 \\
\hline
\end{tabular}

Table 1 shows the design specification of the proposed softwear antenna using silk as a substrate. The actual length of the patch can be determined by solving for L:

$L=\frac{1}{2 f_{r \sqrt{E_{r e f}}}}-2 \Delta L \rightarrow(1)$

$\mathrm{L}_{\text {eff }}=1+2 \Delta \mathrm{L}----(1 \mathrm{a})$

Width leads to radiation efficiency as:

$\frac{V_{0}}{2 f_{r}} \sqrt{\frac{2}{\varepsilon_{r+1}}} \rightarrow(2)$

Effective Dielectric constant of the patch antenna is given by:

$\varepsilon_{\text {reff }}=\frac{\varepsilon_{r+1}}{2}+\frac{\varepsilon_{r-1}}{2} \sqrt{1+\frac{12 h}{w}} \rightarrow(3)$

The extension of the length $\Delta \mathrm{L}$ is:

$(\Delta \mathrm{L} / \mathrm{h})=(0.412(\varepsilon(\mathrm{reff}+0.3) \times(\mathrm{w} /(\mathrm{h}))+0.264)) /\left(\varepsilon_{\mathrm{reff}}-0.258\right)(\mathrm{w} / \mathrm{h}$ $+0.8)----(4)$

Figure 3, shows the design of the proposed antenna. Figures 4 and 5 represent $S_{11}$ and radiation pattern of the proposed antenna.

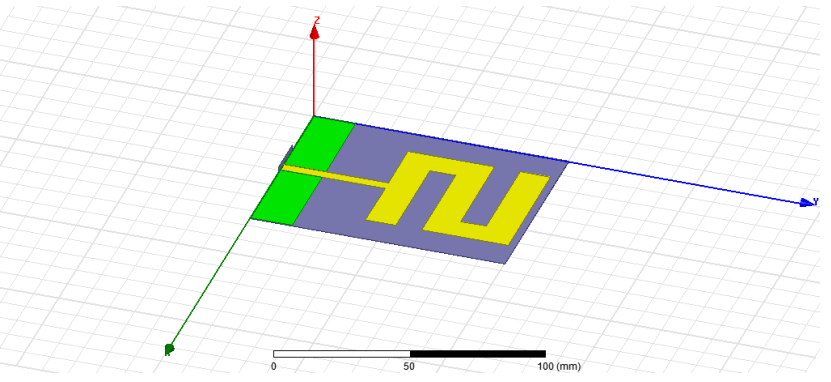

Figure 3. Z-shape soft wearable antenna using silk substrate.

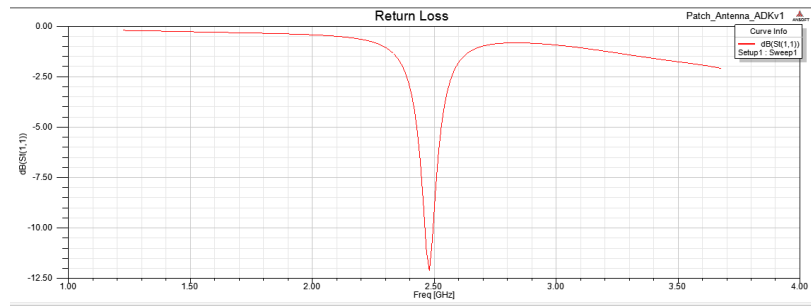

Figure 4. Soft silk substrate wearable antenna working in ISM.

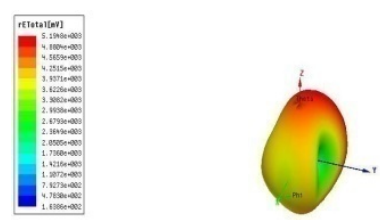

Figure 5. Radiation pattern of the proposed antenna. 


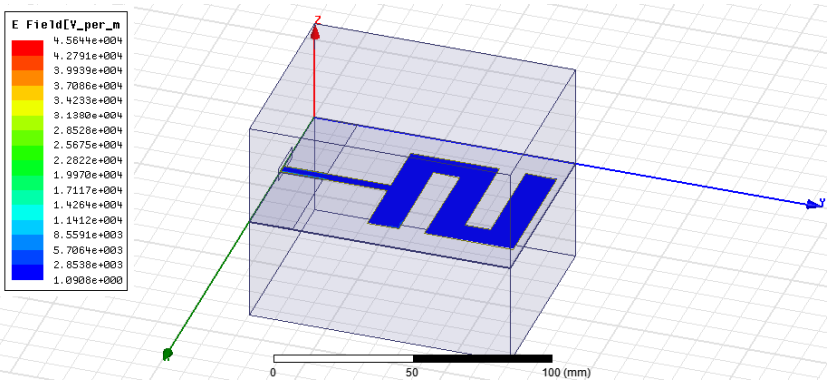

Figure 6. E-field pattern of the proposed antenna.

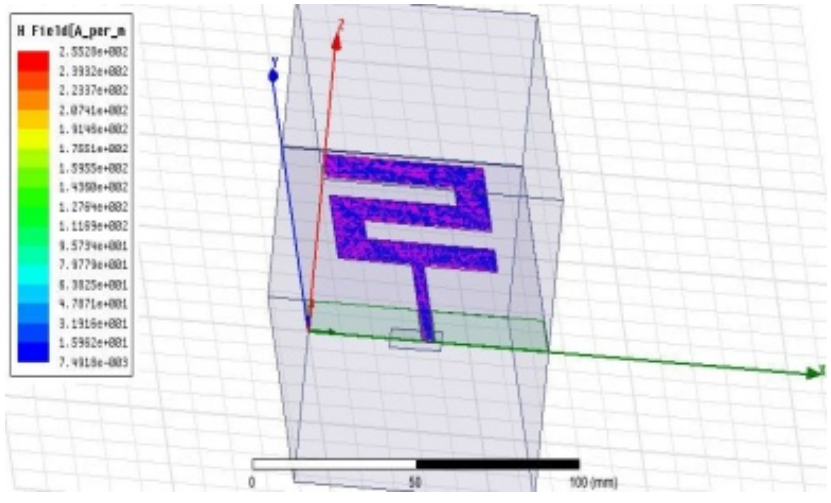

Figure 7. H-field pattern of the softwearable silk antenna.

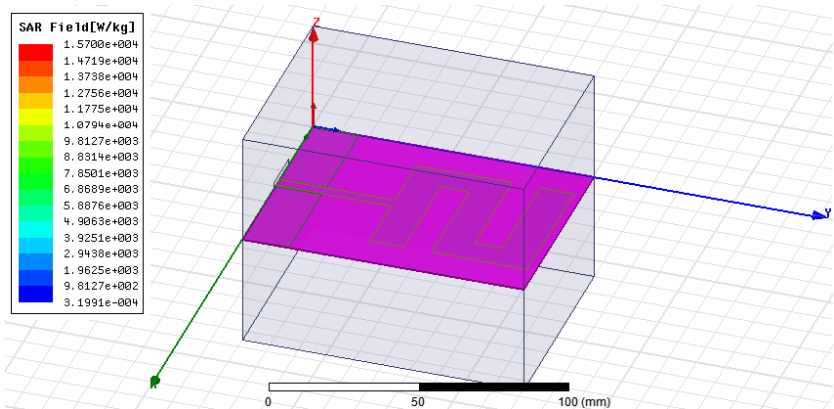

Figure 8. Specific absorption rate of the proposed antenna.

$\mathrm{E}$ and $\mathrm{H}$-field pattern, specific absorption rate of the proposed antenna was shown in Figures 6-8 respectively.

A reduced SAR factor is obtained when silk substrate is used in this proposed antenna.

From Table 2 it was observed that for all the substrates in the proposed antenna achieves a good gain and the frequencies are resonating in the ISM band.

Specific Absorption Rate (SAR) is also reduced when silk substrate is used in the proposed antenna and also other performances like E-field, H-field are also achieved in free space propagation (Figure 9).

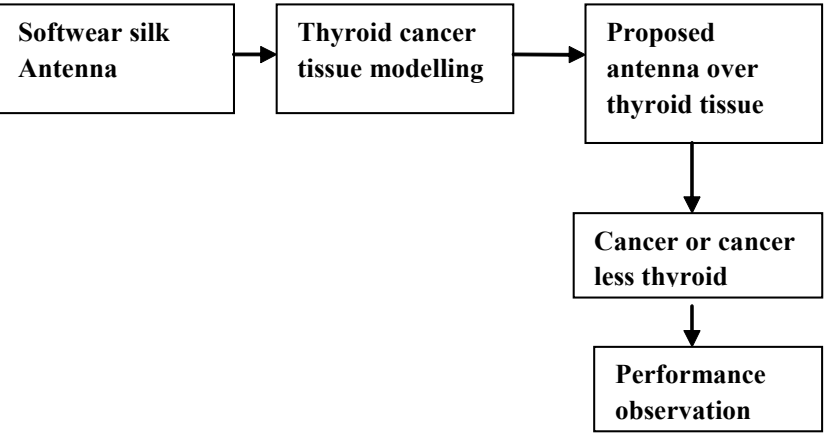

Figure 9. Work flow of placement of softwear antenna on thyroid gland.

\section{Performance of Antenna on Placement of Thyroid Gland}

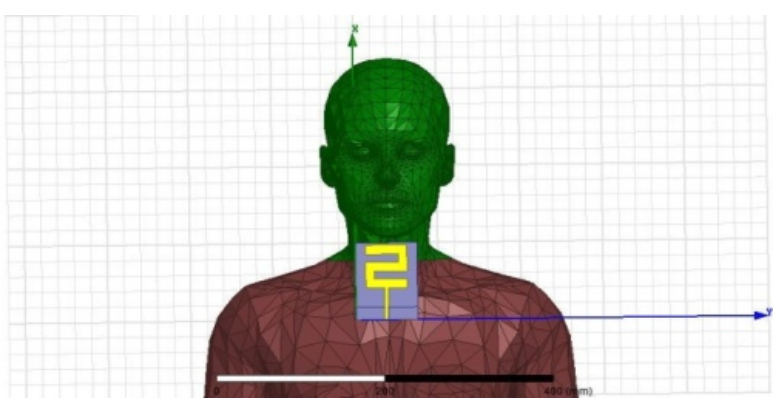

Figure 10. Placement of softwear antenna on human phantom model a front view.

Performance of antenna on thyroid gland has been performed by high dielectric constant of Lizzy phantom model. The front view and propagation in $\mathrm{Z}$-axis has been shown in Figure 10. And the placement of antenna in side view showed in Figure 11 , respectively.

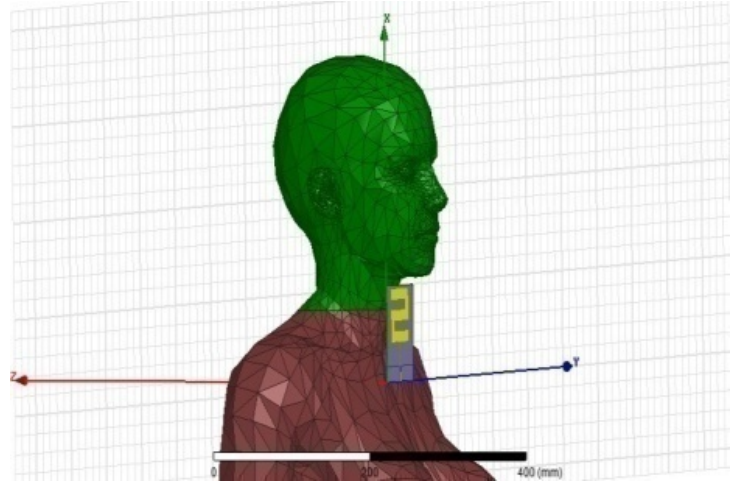

Figure 11. Placement of softwear antenna on human phantom model a side view.

The simulation result of its discrepancy after placing the soft silk substrate wearable patch antenna has been shown in the following figures. 


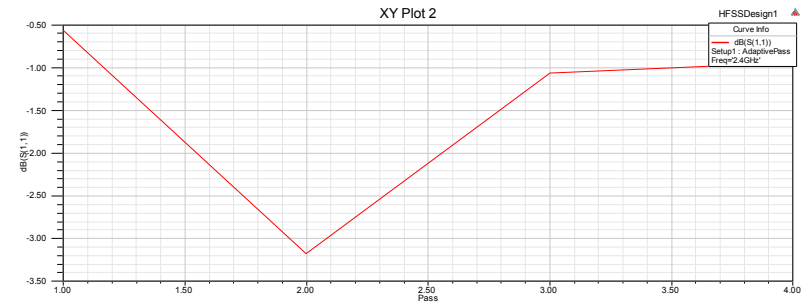

Figure 12. Working frequency of Z-patch soft silk wearable antenna on cancer less thyroid gland $\varepsilon_{r}=1.5$.
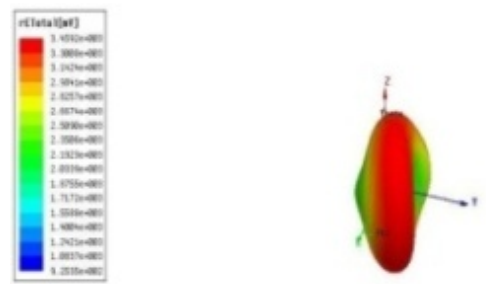

Figure 13. Variations in radiation pattern after placing on cancer less gland.

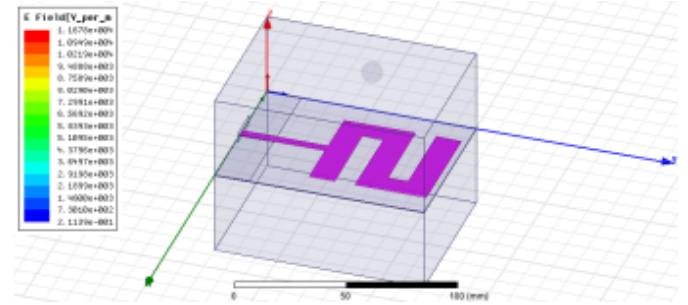

Figure 14. E-field variations after placing on cancer less gland.

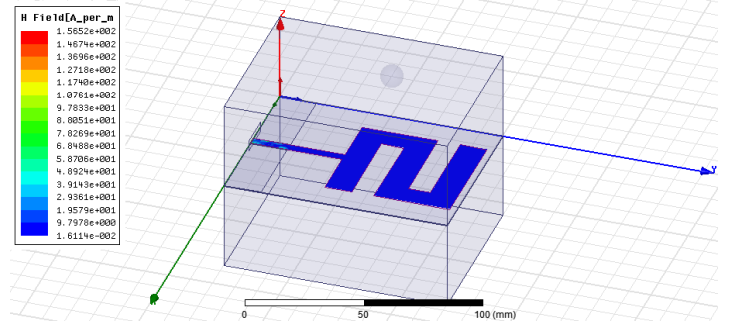

Figure 15. H-field variation after placing on cancer less thyroid gland.
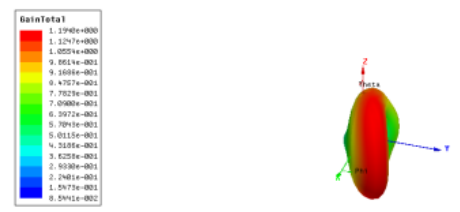

Figure 16. Gain variations after placing on cancer less gland.

After placing the proposed antenna on human phantom model thyroid gland $\varepsilon_{\mathrm{r}}=1.5$ variation in performance has been observed. Figures 12 and 13 show the variation in $\mathrm{S}_{11}$, radiation pattern, and Figures 14-16 show E, H-field pattern and a performance change in gain was observed.

\section{Performance of the Antenna on Placement of Cancer Thyroid Gland}

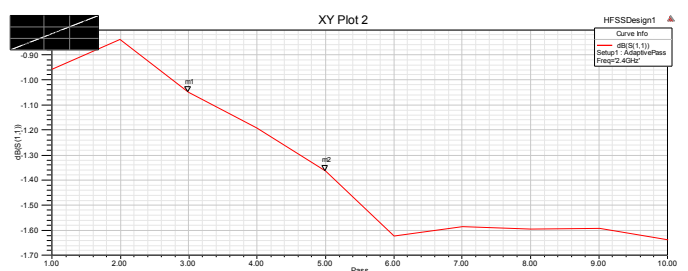

Figure 17. Working frequency of Z-patch softwear antenna on cancer thyroid gland $\varepsilon_{r}=4.5$.
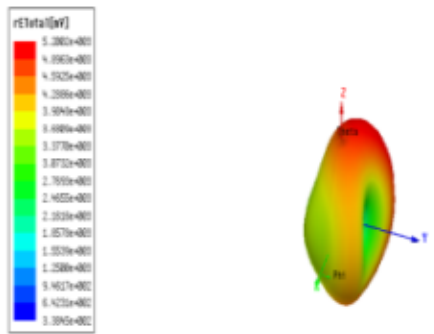

Figure 18. Variation in radiation pattern of the proposed antenna on cancer thyroid gland.
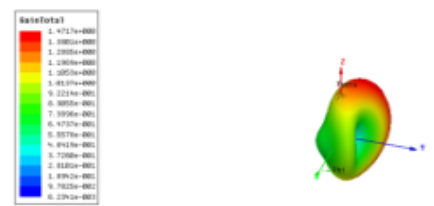

Figure 19. Variation in gain of the proposed antenna on cancer thyroid gland.

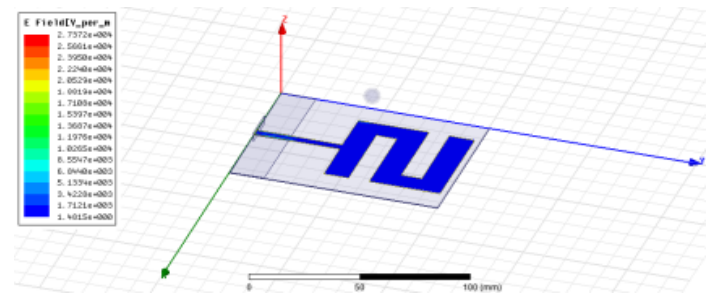

Figure 20. Variation in E-field pattern of the proposed antenna on cancer thyroid gland.

Figures 17-19 show the various performance of variations in $\mathrm{S}_{11}$, Radiation pattern and gain after placing the proposed antenna on cancer thyroid gland $\varepsilon_{\mathrm{r}}=4.5$. $\mathrm{E}$ and $\mathrm{H}$ field patterns are shown in Figures 20 and 21. Performance variation is due to the Permittivity of tissues in human body, which has more water content, cancerous tissues having more water content shows the variation in antenna performance, dielectric medium complex value in general given as:

$\varepsilon=\varepsilon_{0}\left(\varepsilon^{\cdot j} \varepsilon^{\cdot}\right)^{\prime}=\varepsilon_{0}\left(\varepsilon-\mathrm{j}\left(\sigma / \omega \varepsilon_{0}\right)---(5)\right.$

$\varepsilon_{0}$ permittivity in free space. 
$\varepsilon \cdot$ wavelength of EM waves in medium.

$\varepsilon{ }^{\cdots}$ comprises of conductivity and electrical heating in the medium.

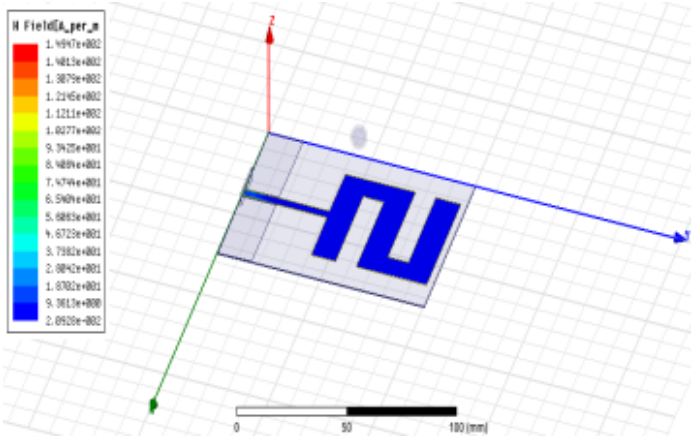

Figure 21. Variation in H-field pattern of the proposed antenna on cancer thyroid gland.

Above Table 3 are the different parameters of the designed Zpatch antenna with and without thyroid gland cancer cells. On careful observation it is found that there is a change in every parameter. The working frequency of the antenna without thyroid cancer is $2 \mathrm{GHz}$ whereas for antenna with thyroid cancer is $2.9 \mathrm{GHz}$. The Directivity of antenna is the flow of radiation in one direction to the average flow in all directions. The directivity performance of antenna without and with thyroid cancer cells is $1.17 \mathrm{~dB}$ and $1.45 \mathrm{~dB}$ respectively. The amount of electric current absorbed per unit area is the E-Field distribution of the antenna [5-8]. The electric field intensity when placed on antenna without and with thyroid cancer is $7.17(\mathrm{~V} / \mathrm{m})$ and $11.4(\mathrm{~V} / \mathrm{m})$ respectively. The ability of the antenna to direct the input power into radiation in a particular direction and is measured at the peak radiation intensity which is defined as gain. When antenna is placed on human model, the gain without thyroid cancer is $1.19 \mathrm{~dB}$ whereas gain of thyroid gland cancer is $1.67 \mathrm{~dB}$. The amount of magnetic field per unit area, defines the $\mathrm{H}$-field intensity of the antenna which, when placed on human model with and without thyroid cancer is $6.06(\mathrm{~A} / \mathrm{m})$ and $6.25(\mathrm{~A} / \mathrm{m})$ respectively. From the above performance observation, cancer gland and cancer less gland can be detected by the performance changes of the antenna. The (specific absorption rate) SAR is measured for (1 $\mathrm{W} / \mathrm{kg}$ ) of the tissue of the thyroid gland. This shows a reduction in SAR value when placing on the cancer thyroid and cancer less thyroid gland and it shows the proposed antenna is suitable for sensing the thyroid cancer cells $[9,10]$.

\section{Fabricated and Measured Results of the Z- Shaped Soft Wearable Silk Antenna}

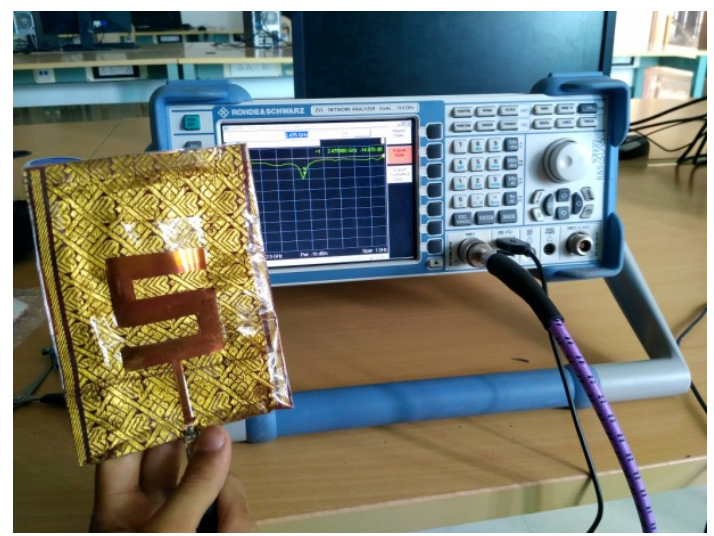

Figure 22. Fabricated soft wearable silk antenna working in ISM band measured in network analyzer.

Fabricated softwear antenna using silk substrate using network analyzer is shown in Figure 22, which shows the $\mathrm{S}_{11}$ as 2.48 $\mathrm{GHz}$ and -17.6 as its return loss which is almost equivalent to the simulated results.

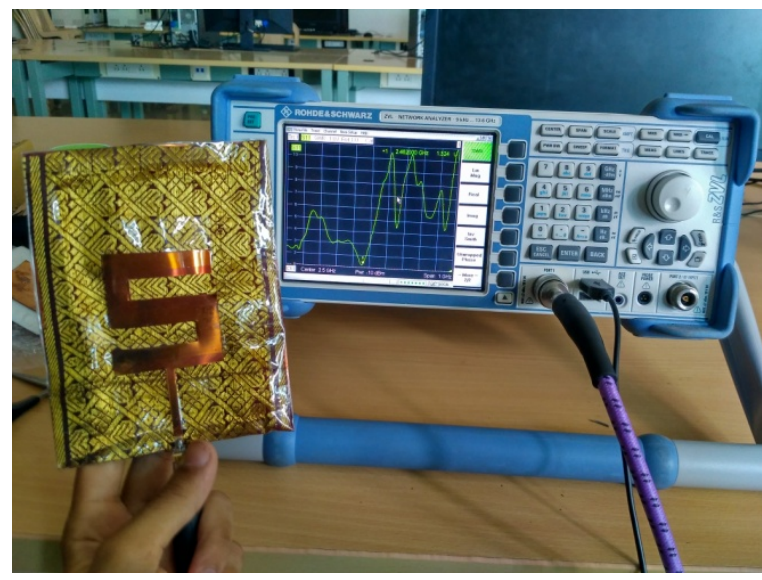

Figure 23. Soft wearable silk antenna showing the VSWR measurement.

Figure 23 shows the VSWR measurement of the proposed antenna showing 1.28 which is approximately equivalent to its simulated one as 1.36 .

The measured results are compared, tabulated and shown in Table 4. The measured results are almost approximately equal when compared with the simulated one.

Table 2. Simulation results of softwear antenna in free space for different substrates.

\begin{tabular}{|c|c|c|c|c|c|c|c|c|}
\hline Substrate & $\begin{array}{l}\text { Dielectric } \\
\text { constant }\end{array}$ & $\begin{array}{l}\text { Working } \\
\text { frequency }(\mathrm{GHz})\end{array}$ & Gain (dB) & VSWR & E-Field (V/m) & H-Field (A/m) & SAR (W/Kg) & Directivity (dB) \\
\hline Paper & 3.4 & 1.8 & 17.3 & 1.7 & 13.5 & 7.059 & 1.57 & 1.44 \\
\hline FR4 epoxy & 3.5 & 1.9 & 3.24 & 1.4 & 15.2 & 6.475 & 1.22 & 1.31 \\
\hline Silk & 2.5 & 2.5 & 7.9 & 1.1 & 19.6 & 6.385 & 0.65 & 1.45 \\
\hline
\end{tabular}




\begin{tabular}{llllllllll}
\hline Polyester & 1.9 & 2 & 3.9 & 1.2 & 15 & 8.939 & 2.55 & 1.44 \\
\hline
\end{tabular}

Table 3. Simulation results of the proposed antenna working on free space, on thyroid gland without and with cancer.

\begin{tabular}{|c|c|c|c|c|c|c|c|c|c|}
\hline Antenna performance & $\begin{array}{l}\text { Dielectric } \\
\text { constant }\end{array}$ & $\begin{array}{l}\text { Working frequency } \\
\text { (GHz) }\end{array}$ & $\begin{array}{l}\text { Directivity } \\
\text { (dB) }\end{array}$ & VSWR & $\begin{array}{l}\text { Radiation } \\
\text { pattern }(\mathrm{mv})\end{array}$ & $\begin{array}{l}\text { E-Field } \\
(\mathrm{V} / \mathrm{m})\end{array}$ & $\begin{array}{l}\text { Gain } \\
\text { (dB) }\end{array}$ & $\begin{array}{l}\text { H-Field } \\
(\mathrm{A} / \mathrm{m})\end{array}$ & $\begin{array}{l}\text { SAR } \\
(1 \mathrm{~W} / \mathrm{Kg})\end{array}$ \\
\hline On free space & 2.5 & 2 & 1.26 & 1.36 & 18.1 & 19.6 & 7.24 & 6.38 & 0.6 \\
\hline On cancer less thyroid gland & 1.5 & 2 & 1.17 & 1.16 & 12.4 & 7.17 & 1.19 & 6.25 & 1.2 \\
\hline On thyroid gland with cancer cells & 4.5 & 2.9 & 1.45 & 1.19 & 17.1 & 11.4 & 1.67 & 6.06 & 1.14 \\
\hline
\end{tabular}

Table 4. Simulated and measured results of the flexible wearable silk antenna using network analyser.

\begin{tabular}{llll}
\hline Observations & $\mathbf{S}_{11}$ & Return loss (dB) & VSWR \\
\hline Simulated result & $2.5 \mathrm{GHz}$ & -12.5 & 1.36 \\
\hline Measured result & $2.48 \mathrm{GHz}$ & -17.6 & 1.28 \\
\hline
\end{tabular}

\section{Conclusion}

An innovative Z-patch soft wearable silk antenna working in ISM band using four different substrates has been designed and various performances were observed. On Analysis and comparison of the results, silk antenna is used as the substrate, as it has low SAR, when compared to other substrates. Due to its low SAR value and as it is a wearable silk antenna, having wearable and textile properties, the designed antenna can be used in biomedical wearable applications. The designed antenna was placed on human thyroid gland to obtain the performance whether the cancer cells are present or not in the thyroid gland. Different parameters such as E-Field, gain are considered and accordingly the presence or absence of thyroid cancer cells is detected. Due to the presence of high water content cancer cells the observations were made in the performance of the antenna, it is perceptive to observe the changes when it is wear on thyroid gland since the permittivity between cancer and cancer fewer glands varies, the performance of the antenna also changes consequently. Hence by using this proposed antenna on human body and by appraising its results, the presence or absence of thyroid cancer can be detected. The fabricated antenna has been measured using network analyzer, and the simulated and measured results were compared the result shows the simulated $\mathrm{S}_{11}$ and VSWR are approximately equal and working in ISM band is suitable for industrial, scientific and medicine purpose. The Proposed one should be placed on thyroid gland phantom and in real tissues in future to ensure the performance by using the network analyzer.

\section{References}

1. Sudhir S, Mangilal A, Azadeh H, Parvin G, Kody V. Breast tumor detection by flexible wearable antenna system. Food and Beverage 2012.
2. Pankaj KS, Subodh KT, Rahul S, Ashok K. Design \& simulation of microstrip antenna for cancer diagnosis. IJSER 2009; 824-659.

3. Daya MS, Narada MMB, Dilip VY, Chaitanya SVSK. Development of wearable antennas with different cotton textiles. J Eng Res Appl 2014; 4: 2248-9622.

4. Mantash M, Tarot AC, Collardey S, Mahdjoubi K. Investigation of flexible textile antenna and AMC reflector. Int J Antenna Propagation 2012.

5. Saadat Hanif D, Jameel A. Wearable textile antenna design in body centric wireless communications: a systematic literature review. Biomed Res 2017; 28: 3716-3720.

6. Locher I, Klemm M, Kirstein T, Troester G. Design and characterization of purely textile patch antennas. IEEE Trans Adv Packaging 2006; 29: 777-788.

7. Hai SZ, Shun LC. Numerical and experimental analysis of wideband e-shaped patch textile antenna. Progress In Electromagnetics Res 2013; 45: 163-178.

8. Sudhir S, Mangilal A. Microstrip antennas for direct human skin placement for biomedical applications. PIERS Proceedings, Cambridge, USA 2010.

9. Rexiline Sheeba I, Jayanthy T. Design and Analysis of a low cost, flexible softwear antenna for an ISM band working in different bending environment. Springer 2016.

10. Peter SH, Yang H. Antennas and propagation for body centric wireless communications. IEEE 2006.

\section{*Correspondence to}

Rexiline Sheeba I

Sathyabama Institute of Science \& Technology

Chennai

India

E-mail: sheebarexlin@gmail.com 